\title{
Flocculating Properties of Water-Soluble Polymer-Colloid Complexes of Aluminoxane Particles with Weakly Charged Cationic Polyelectrolytes ${ }^{1}$
}

\author{
Stanislav Radchenko, Ivan Novakov, Philipp Radchenko, Cong Le Van, Elena Rybakova \\ Volgograd State Technical University, Volgograd, Russia \\ E-mail:radchenko@vstu.ru \\ Received January 7, 2011; revised February 19, 2011; accepted March 22, 2011
}

\begin{abstract}
The flocculating properties of polymer-colloid complexes (PCCs) formed via noncovalent interactions of positively charged aluminoxane particles (APs) with macromolecules of weakly charged cationic acrylamide copolymers from the Praestol and Organopol series have been studied. The PCCs that spontaneously formed during mixing of sols of a high-basicity aluminum polyhydroxochloride (APHC) with aqueous solutions of the copolymers exhibit high flocculating ability under the conditions of gravity sedimentation of the model kaolin dispersion with $C_{d}=8 \mathrm{~g} / \mathrm{dm}^{3}$, and their efficiency exceeds both that of the copolymers and the earlier obtained PCCs with nonionogenic polyacrylamide (PAA). In contrast to weakly charged polycationites, the fully charged KF-99 polyelectrolyte does not form PCCs and the products of its mixing with APHC do not reveal an increased flocculating effect.
\end{abstract}

Keywords: Polymer-Colloid Complexes of Aluminoxane Particles, Weakly Charged Cationic Polyelectrolytes, Kaolin, Flocculation

\section{Inroduction}

At present, the problem of water supply acquires a global strategic significance since, firstly, water turned out to be the main deficit of the XXI century, and, secondly, control over high quality and safety of consumable water became urgent. The latter factor is associated with the task to remove particles less than $10 \mu \mathrm{m}$ in size from water because precisely these particles may adsorb contaminants, pathogenic microorganisms, and viruses that occur in open water reservoirs. It is noteworthy that, among a great diversity of methods for natural water purification, coagulation based on the use of special reagents is the most economically attractive and large-scale. The conventional water treatment technologies make use of aluminum and iron salts, and aluminum basic chlorides $(\mathrm{ABCs})$ have found wide use in recent years. The growing requirements on the content of harmful contaminants in water, including the demand for reduction in the residual amounts of aluminum, which is a neurotropic toxic substance, stimulate the search for more

\footnotetext{
${ }^{1}$ We thank the Russian Foundation for Basic Research for the financial
} support of this work, project No. 08-03-00709-a. complicated reagent compositions ensuring a high degree of water purification at minimal doses of such compositions.

In practice of water treatment, the joint use of polyvalent metal salts and polymer flocculants, above all of polyacrylamide (PAA), has long been in use. These compositions are mainly applied to improve flocculation in sedimentation chambers and to reduce the time of water clarification. However, during the course of hydrolysis of salts, metal ions may form ion-coordination bonds with ion-exchange groups of flocculant macromolecules, thereby changing the conformational and hydrodynamic parameters of macromolecules $[1,2]$. That is why depending on the regime and order of reagent addition, both synergetic and antagonistic effects may occur in the purification process [3,4]. In [5-10], more complicated compositions based on polymer inorganic salts or their mixtures with organic polymers are developed. Such compositions often involve rather complex preparation procedure and are mostly intended for sewage purification.

A new type of composition reagents has been designed in recent years. These reagents are formed on the 
nanosized level as polymer-particle and polymer-colloid complexes (PCCs) [11-17]. Such systems are distinguished by easy preparation: they spontaneously form through intermolecular association via noncovalent bonds. As a result, well-defined thermodynamically stable supramolecular structures arise with sizes from 10 $\mathrm{nm}$ to $100 \mu \mathrm{m}$ [18]. As regards use in practice, the PCCs based on sols of high-basicity aluminum polyhydroxochloride (APHC) and polyacrylamide have been studied most extensively [19-21]. The composition of such polycomplexes suggests their use as stability regulators for dispersed systems among which are both natural waters and sewages. It was shown that these polycomplexes offer promise as high-efficient reagents in water treatment for household water use [22-24] and in purification of sewages [25-27]. The said PCCs are prepared on the basis of nonionogenic PAA. At the same time, the ion-active acrylamide copolymers are used for water purification. These copolymers differ both in the sign of charge and in the content of ionogenic groups. The feasibility of formation of PCCs of such copolymers with positively charged particles of APHC sols is obviously determined by the chemical structure of the polymer reagent.

Generally, the ability to form PCCs arises from the fundamental property of macromolecules-a high cooperativity of a system of weak interactions (electrostatic, hydrogen-bonding, hydrophobic, and donor-acceptor) between linear polymers and the surface of colloid particles. Therefore, the area of this surface plays the decisive role on condition that reactive centers occur on it. As it was shown in [15], that is why low-molecular-mass aluminum salts do not form PCCs with polyacrylamide, while high-basicity APHC sols, which represent the dispersed system of aluminoxane particles (APs) mostly composed of species with a size of $4.6 \mathrm{~nm}$ and a specific surface area of $3 \times 10^{2} \mathrm{~m}^{2} / \mathrm{cm}^{3}[28,29]$ form soluble PCCs with the nonionogenic PAA.

The realization of noncovalent interactions that provide the stability of the polycomplexes being formed and their solubility in water is another significant condition of PCC formation. In terms of adopted ideas about the cooperativity of noncovalent interactions in the polymerparticle system, we have recently studied the formation of PCCs during interaction of positively charged APs in APHC sols with weakly charged cationic polyelectrolytes (WCPEs) from the Praestol and Organopol series [30]. It was found that PCCs are formed if the content of cation-active groups in the polymer chain is small. In this case, at a high molecular mass of flexible-chain acrylamide copolymers, in diluted aqueous solutions, a appreciable quantity of lengthy uncharged segments of the polymer chain exists which form cooperative bonds with the surface of APs as in the case of PAA-based polycomplexes $[20,21]$.

The goal of this work is to study the flocculating properties of water-soluble PCCs based on the weakly charged cationic polyelectrolytes and aluminoxane particles of aluminum polyhydroxochloride hydrosols.

\section{Experimental}

APHC was prepared from the aluminum alloy as described in [31] in the form of aqueous solution. The content of aluminum was $12.6 \mathrm{wt} \%$, and the atomic ratio was $\mathrm{Cl}: \mathrm{Al}=0.46$.

According small-angle X-ray scattering, the aqueous suspension of APHC was the mixture of two types of colloid particles with significantly different sizes (4.6 and $60 \mathrm{~nm}$ ). The volume content of $60 \mathrm{~nm}$ particles did not exceed $1 \%$ with respect to the volume of all scattering particles. The $4.6 \mathrm{~nm}$ particles were the dense subunits of the thread-like spatial structure with a fractal dimensionality of $\mathrm{d}_{\mathrm{f}} \approx 1.0$ [29].

As weakly charged cationic polyelectrolytes, the samples of acrylamide copolymers from the Praestol and Organopol series were used. These samples differed in the chemical structure, molecular mass, and content of cationic (quaternary ammonium) groups. In contrast to weakly charged polyelectrolytes, a strong cationic KF-99 polyelectrolyte, poly(N,N,N,N-trimethylmethacryloyloxyethylammonium methylsulfate), was also used in this study. This choice was associated with a wide application of these copolymers in practice and their high molecular mass. Since the copolymer samples used in this study were commercial and their characteristics were of approximate character, we have studied their physicochemical properties. The quantity of cationic groups in WCPEs was determined through the potentiometric titration with $\mathrm{AgNO}_{3}$ solution using a silver indicator electrode. The viscosity of WCPE solutions was measured at a temperature $30^{\circ} \mathrm{C}$ in aqueous and aqueous-saline solutions by means of a Cannon-Ubbelohde-75/008 viscometer with $\mathrm{D}_{\text {cap }}=0.54 \mathrm{~mm}$. The characteristics of WCPEs are summarized in the Table $\mathbf{1 .}$

To prepare the PCCs, the aqueous solutions of WCPEs $(\mathrm{C}=0.05 \mathrm{~g} / \mathrm{dl})$ were mixed with the calculated weighed portion of APHC (at different $\mathrm{Al}^{3+}$ : WCPE unit molar ratios), and the mixture was allowed to stand for 1 day at room temperature.

The flocculating ability of PCCs was estimated with the use of the model kaolin suspension in thee gravity sedimentation regime.

The kaolin dispersion (the concentration of the dispersed phase was $8 \mathrm{~g} / \mathrm{dm}^{3}$ ) was prepared from kaolin of the technical grade and tap water; the dispersion was 
Table 1. Characteristics of the copolymers.

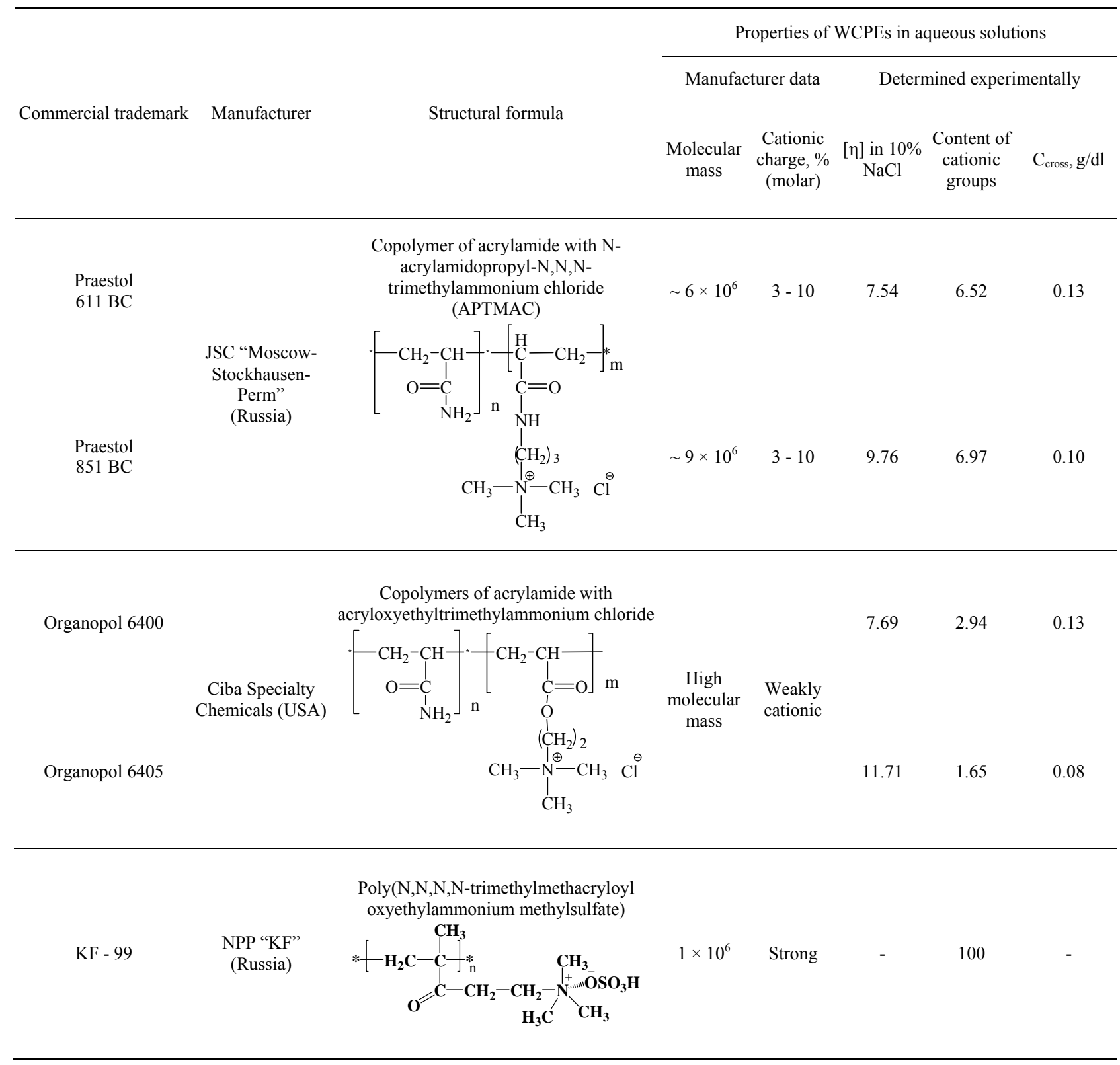

allowed to stand for $1 \mathrm{~h}$ for swelling, then it was thoroughly stirred and poured into cylinders with $\mathrm{V}=250$ $\mathrm{cm}^{3}$. A certain volume (a dosage) of reagent solution was added in every cylinder; the mixture was stirred with a circular stirrer for $30 \mathrm{~s}$ and allowed to settle for $20 \mathrm{~min}$. The upper clarified layer was collected, and its optical density was measured on a Specol-1300 spectrophotometer $(\lambda=540 \mathrm{~nm}$, and $L=1-3 \mathrm{~cm})$.

\section{Results and Discussion}

As is known, the removal of mechanical suspensions and colloid particles is the first step in the flow chart of water purification. In many cases, colloid particles carry the surface negative charge. Hence, due to mutual electrostatic repulsion, such dispersions are sufficiently stabilized. For the same reason, the neutralization of the surface charge is the necessary step in destabilization of colloid dispersions. Moreover, owing to the aggregation of particles, floccules are formed. This process is favored by the addition of polymer flocculants to water during purification. Coagulation and the early stage of flocculation are rapid processes, and their separation presents a challenge. The enlargement of floccules (flocculation) proceeds at a smaller rate. In practice, both separate successive addition of reagents and their simultaneous 


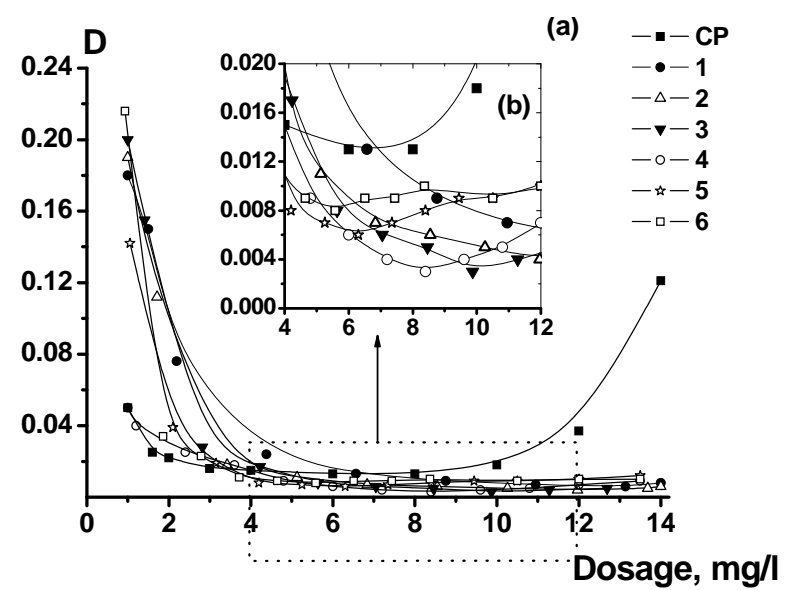

Figure 1. Dependence of the optical density (D) of the kaolin dispersion during flocculation on the dosage of copolymer (CP) (Praestol 611BC) and the related PCCs at different $\mathrm{Al}^{3+}: \mathrm{CP}$ unit molar ratios in the initial reagent mixture.

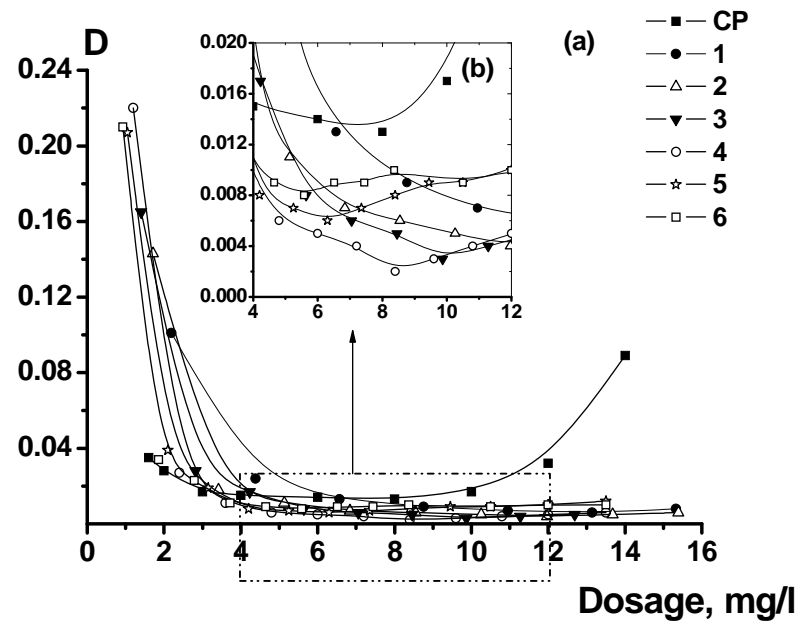

Figure 2. Dependence of the optical density (D) of the kaolin dispersion during flocculation on the dosage of copolymer (CP) (Praestol 851BC) and the related PCCs at different $\mathrm{Al}^{3+}$ :CP unit molar ratios in the initial reagent mixture.

addition are employed.

In this connection, in what follows, we present our experimental data on the flocculating properties of polycomplex reagents, PCCs, and on separate effects of the coagulant (the inorganic aluminum salt) and the flocculant (the copolymer of acrylamide) under different regimes of their introduction into the purified model system. Aluminum sulfate (AS) and low-basicity aluminum chloride $(\mathrm{ABC})$, which are conventionally employed in water treatment, were used in this study. The kaolin dispersion in water with a content of the dispersed phase 8 $\mathrm{g} / \mathrm{dm}^{3}$ was employed as a model dispersion. All experiments were performed at a temperature $25-27^{\circ} \mathrm{C}$ (the natural environment indoors). To get comparative data, flocculation was examined with the use of individual

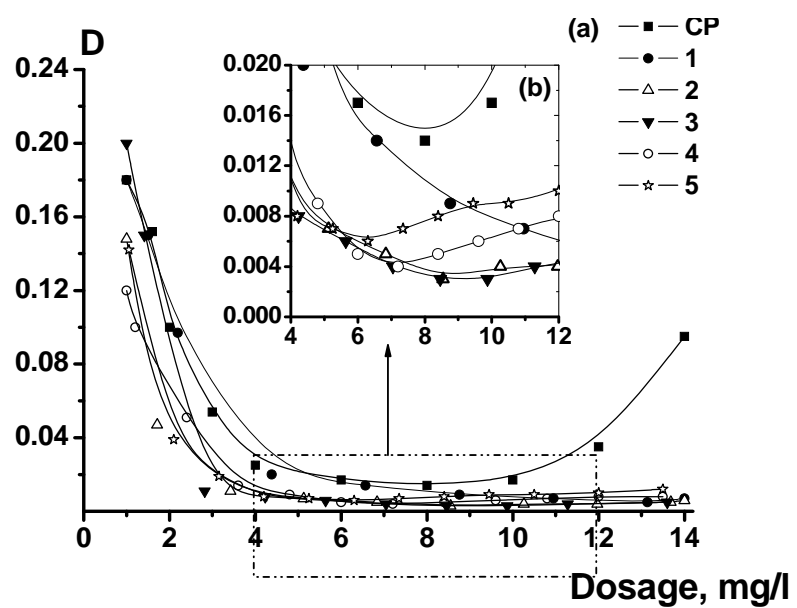

Figure 3. Dependence of the optical density (D) of the kaolin dispersion during flocculation on the dosage of copolymer (CP) (Organopol 6400) and the related PCCs at different $\mathrm{Al}^{3+}: \mathrm{CP}$ unit molar ratios in the initial reagent mixture.

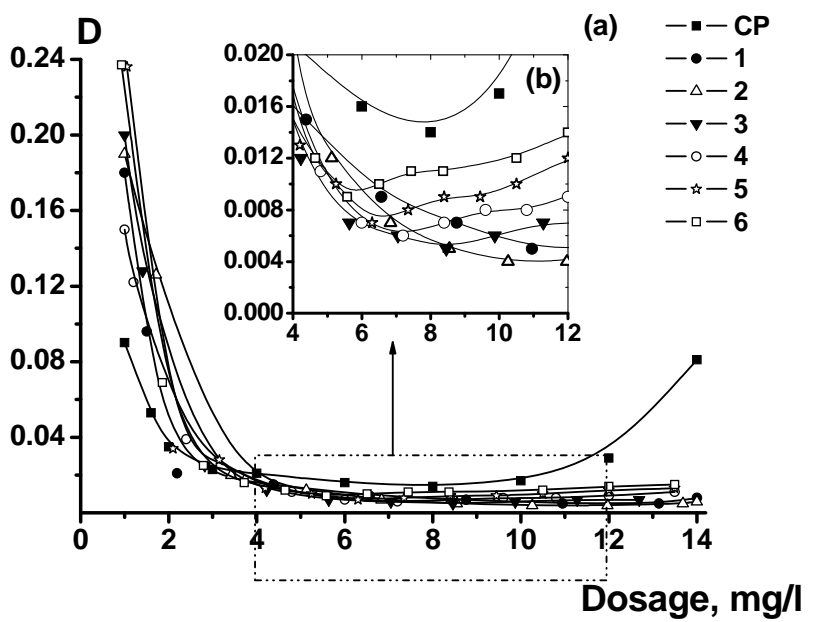

Figure 4. Dependence of the optical density (D) of the kaolin dispersion during flocculation on the dosage of copolymer (CP) (Organopol 6405) and the related PCCs at different $\mathrm{Al}^{3+}$ :CP unit molar ratios in the initial reagent mixture.

copolymers and PCCs based on nonionogenic PAA and APHC [24]. Figures 1-4 demonstrate a variation in the optical density of kaolin dispersion during flocculation with different dosages of polycomplexes of various compositions and individual cationic copolymers.

The following designations are used in Figures 1-4: $\mathrm{CP}$ is copolymer; $1,2, \cdots, 6$ refer to the PCCs with $\mathrm{Al}^{3+}$ to $\mathrm{CP}$ unit molar ratios in the initial mixture equal to $1: 1$, $2: 1, \cdots, 6: 1$, respectively.

As follows from the above data, the behavior of all CPs (Praestol and Organopol) is typical for highmolecular-mass polyelectrolytes; that is, they are characterized by the optimal dosage interval $(4-6 \mathrm{mg} / \mathrm{dm} 3)$ in flocculation. An excess of these dosages leads to stabili- 
zation of dispersions. On the contrary, the PCCs demonstrate a wider dosage interval and in terms of their efficiency surpass the initial CPs and decrease the optical density to a minimum level of $0.003-0.004$. A certain difference is observed for the PCCs of different compositions (Figures 1b-4b). In all cases, the highest activity is demonstrated by the PCCs prepared at the $\mathrm{Al}^{3+}$ : CP elemental unit (molar) ratio in the range from $3: 1$ to $4: 1$. A further increase in the amount of $\mathrm{Al}^{3+}$ in the reagent mixture brings about a certain decline in the flocculating ability (curves 5 and 6 in Figures 1-4).

As was mentioned above, under the combined use of inorganic coagulants and polymeric flocculants, the synergetic effect may be observed. In our opinion, a high activity of the PCCs cannot be associated with this phenomenon but results from the individual nature of polycomplexes. To confirm this suggestion, special experiments on flocculation with mechanical mixtures of CPs with aluminum salts $\left(\mathrm{Al}_{2}\left(\mathrm{SO}_{4}\right)_{3}\right.$ and $\left.\mathrm{ABCs}\right)$ were performed at various orders of their addition to the dispersion, namely, first the coagulant (the salt) and then the flocculant (CP) and vice versa.

Figures $\mathbf{5}$ and $\mathbf{6}$ display variation in the optical density of the kaolin dispersion during its treatment with different dosages of individual Praestol 611BC and Organopol 6400 , the related PCCs, and the mixtures of Praestol $611 \mathrm{BC}$ and Organopol 6400 with $\mathrm{ABCs}$ and $\mathrm{Al}_{2}\left(\mathrm{SO}_{4}\right)_{3}$. With a small difference, similar dependences were obtained for other copolymers, Praestol 851BC and Organopol 6405.

These data show that the PCCs provide the most pronounced clarification at the same dosages and reveal no stabilizing effect under overdosing. It is noteworthy that a similar behavior is observed for the mixtures of the CPs with ABCs. This circumstance is evidently associated with the fact that the ABCs is an equilibrium mixture of aluminum oxychlorides, including those with high basicity and capable of forming PCCs [31]. Thus, during the mixing of ABCs with the CoaPs, the PCCs are formed in the corresponding small amount and these PCCs play a certain role in flocculation.

The synergetic effect that appears, when the coagulant-flocculant mixtures are used, depends on the order of addition of these reagents to water being treated. Figures 7 and 8 demonstrate the data on clarification of the kaolin dispersion at different orders of addition of CP (flocculant) and inorganic salt (coagulant).

With small differences, similar relationships were obtained for other copolymers, Praestol 851BC and Organopol 6405. In this case, the best results were achieved for the PCCs as well. As might be expected, the order of addition of reagents flocculant + coagulant gives the smallest effect. As was shown in [30], the strong polyelectrolyte KF-99 does not form PCCs during its mixing with APHC sols. Figure 9 demonstrates the results of flocculation with pure KF-99 and its mixtures with the APHCs. These data show that all combinations are characterized by smaller effects than those in the case of the PCCs. The effects due to the said combinations are approximately equal and correspond to the use of the KF99 solely. This circumstance indicates the absence of interaction between KF-99 macromolecules and aluminoxane particles.

To elucidate a difference in the flocculating properties of the PCCs of various compositions, the spectrophotometric technique [32] was employed since the conventional technique used to estimate the flocculation effect based on the accumulation of the mass of dispersion precipitating on a torsion balance pan turned out to be inapplicable. In our case, a high rate of floccule sedimentation coagulated with the PCCs caused a high scatter in the experimental data. In the spectrophotometric technique, the optical density of the supernatant taken a certain time after dispersion settling with and without reagent addition was measured. Then, the dimensionless parameter, the clarification effect, was calculated:

$$
E_{\text {clar. }}=\frac{\tau_{D}^{0}}{\tau_{D}}-1
$$

where $\tau_{D}^{0}$ and $\tau_{D}$ are the optical turbidities of the supernatant without and with the addition of reagent, respectively.

$$
\tau_{D}=\frac{2,3 D}{L}
$$

where $\mathrm{D}$ is the optical density of a liquid and $\mathrm{L}$ is the thickness of the liquid layer in the spectrophotometer cell.

Figure 10 depicts relationships for the clarification effect Eclar of the PCCs based on the copolymers under study obtained at different $\mathrm{Al}^{3+}: \mathrm{CP}$ unit (molar) ratios in the initial mixtures and of the individual copolymers determined at the optimal reagent dosage $\left(6 \mathrm{mg} / \mathrm{dm}^{3}\right)$.

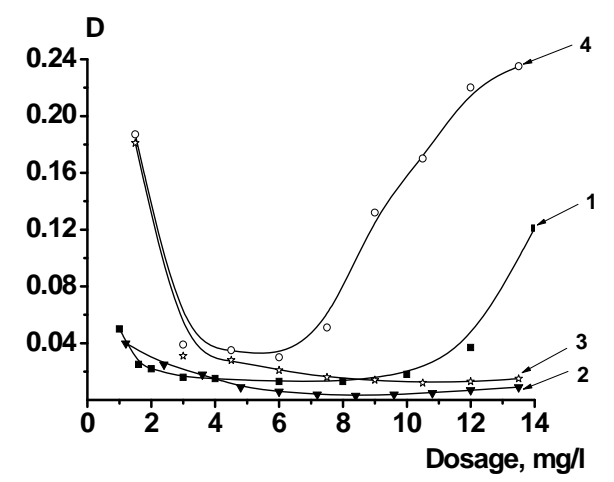

Figure 5. Flocculation of the kaolin dispersion $\left(8 \mathrm{~g} / \mathrm{dm}^{3}\right)$. Curves 1, 2, 3, and 4 refer to Praestol 611BC, the related PCC, Praestol 611BC + ABC, and Praestol 611BC + $\mathrm{Al}_{2}\left(\mathrm{SO}_{4}\right)_{3}$, respectively, at various reagent dosages $\left(\mathrm{mg} / \mathrm{dm}^{3}\right)$. $D$ is the optical density. 


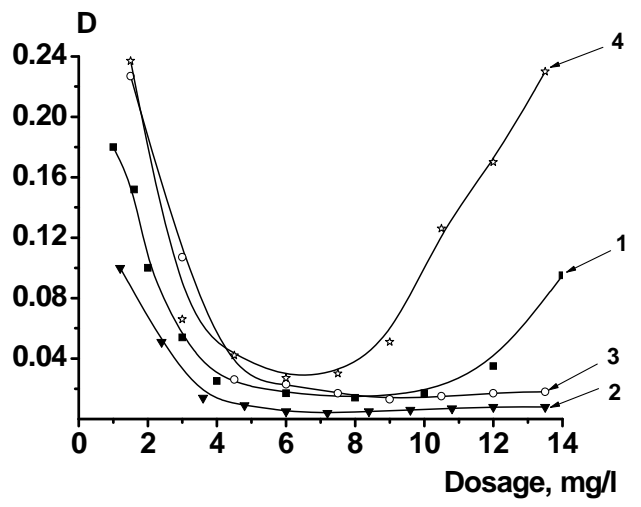

Figure 6. Flocculation of the kaolin dispersion $\left(8 \mathrm{~g} / \mathrm{dm}^{3}\right)$. Curves 1, 2, 3, and 4 refer to Organopol 6400, the related PCC, Organopol $6400+$ ABC, and Organopol 6400+ $\mathrm{Al}_{2}\left(\mathrm{SO}_{4}\right)_{3}$, respectively, at various reagent dosages $\left(\mathrm{mg} / \mathrm{dm}^{3}\right)$. $D$ is the optical density.

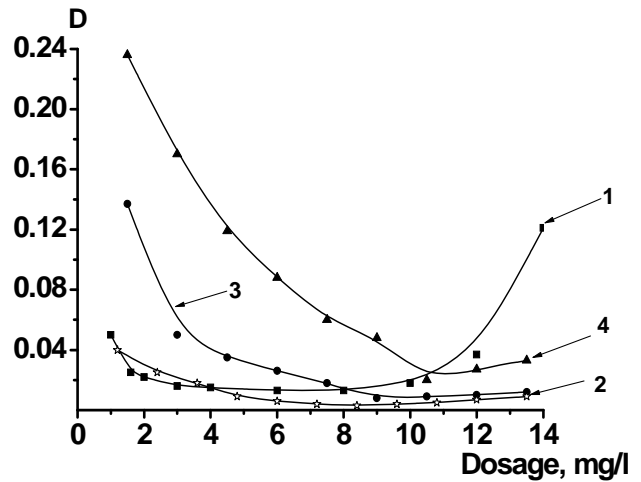

Figure 7. Flocculation of the kaolin dispersion $\left(8 \mathrm{~g} / \mathrm{dm}^{3}\right)$ at different orders of addition of reagents and different reagent dosages $\left(\mathrm{mg} / \mathrm{dm}^{3}\right)$. The numbering of the curves is as follows: 1) Praestol 611BC, 2) the related PCC, 3) coagulant + flocculant, and 4) flocculant + coagulant. D is the optical density.

Figure 11 compares the values of Eclar obtained for the individual copolymers, the related PCCs at the optimal $\mathrm{Al}^{3+}: \mathrm{CP}$ unit molar ratio in the initial mixtures, and mixtures. This figure also demonstrates the data obtained for the PCCs of the nonionogenic PAA and APHC sols [24].

The data described above give us grounds to infer that a high flocculating ability of the PCCs is associated with the individual nature of the polycomplexes that combine the properties of the inorganic coagulant and of the polymer flocculant.

\section{Conclusions}

1) It has been found that the water soluble polymer colloid complexes of weakly charged cationic copolymers of acrylamide with aluminoxane particles of aluminum polyhydroxochlorides sols demonstrate a high floc-

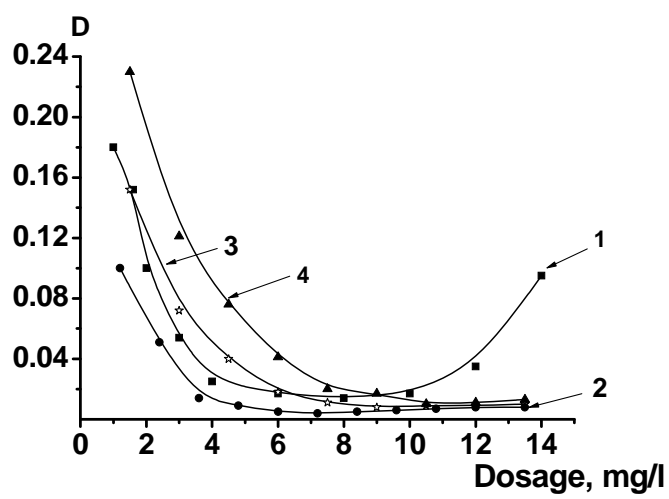

Figure 8. Flocculation of the kaolin dispersion $\left(8 \mathrm{~g} / \mathrm{dm}^{3}\right)$ at different orders of addition of reagents and different reagent dosages $\left(\mathrm{mg} / \mathrm{dm}^{3}\right)$. The numbering of the curves is as follows: 1) Organopol 6400, 2) the related PCC; 3) coagulant + flocculant, and 4) flocculant + coagulant. $D$ is the optical density.

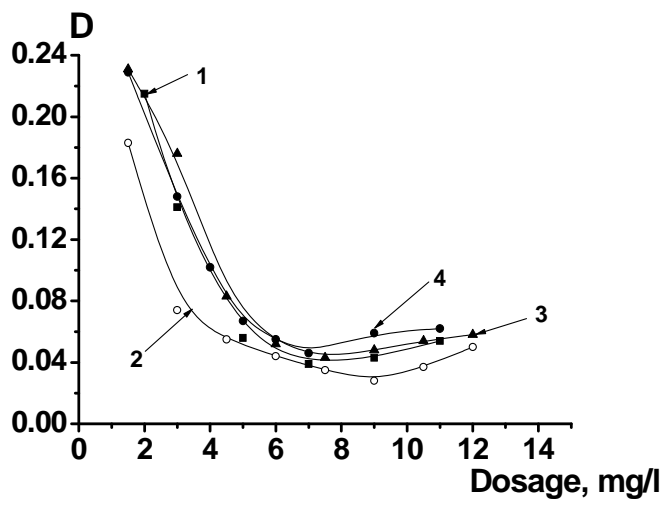

Figure 9. Flocculation of the kaolin dispersion $\left(8 \mathrm{~g} / \mathrm{dm}^{3}\right)$ at different orders of addition of reagents and different dosages of reagents $\left(\mathrm{mg} / \mathrm{dm}^{3}\right)$. The numbering of the curves is as follows: 1) KF-99, 2) mixture of KF-99 and APHC (the PCC analog), 3) coagulant + flocculant, and 4) flocculant + coagulant. $D$ is the optical density.

culating ability. In terms of flocculating activity in the separation of model kaolin dispersion under the regime of gravity sedimentation of the polycomplexes, they surpass the initial cation-active copolymers and the PCCs based on the nonionogenic polyacrylamide.

2) The flocculating activity of the PCCs depends on the ratio of reagents in the initial mixtures and achieves the maximum value for the $\mathrm{Al}^{3+}$ : copolymer unit molar ratios in the range from $3: 1$ to $4: 1$ for different copolymers.

3) A high flocculating activity of the PCCs does not result from the synergetic effect of the mutual action of coagulant (APHCs) and flocculant (WCPEs) but is ex plained by the original nature of the polycomplexes formed during their interaction via nonelectrostatic forces.

4) The fully charged cation-active KF-99 polymer 

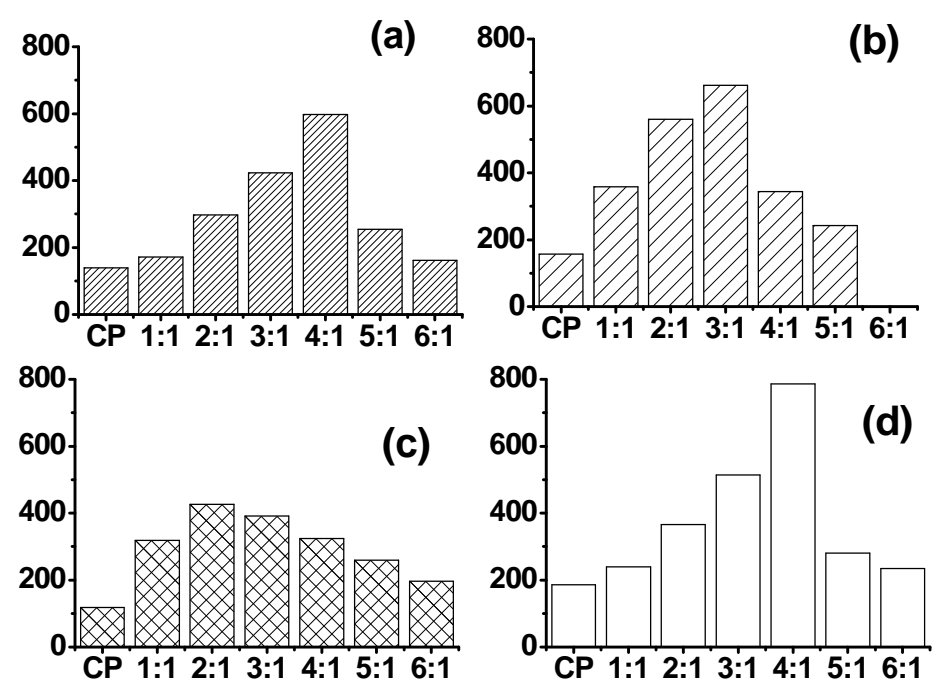

Figure 10. Clarification effects $\left(E_{\text {clar }}\right)$ for the CPs and the related PCCs of different compositions: (a) Praestol 851BC, (b) Organopol 6400, (c) Organopol 6405, and (d) Praestol 611BC. Designations 1:1, 2:1, etc. refer to $\mathrm{Al}^{3+}$ :CP unit molar ratios in the initial reagent mixture.

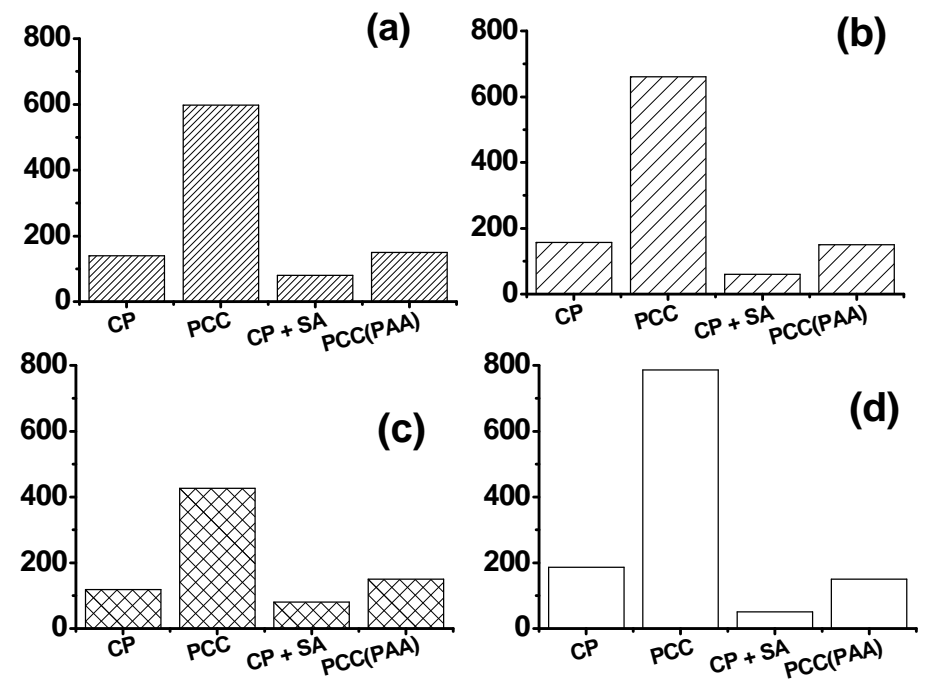

Figure 11. Clarification effects (Eclar) for the individual CPs, the related PCCs at the optimal $\mathrm{Al}^{3+}: \mathrm{CP}$ unit molar ratios in the initial mixtures, mixtures (CP + AS), and the PAA-based PCCs: (a) Praestol 851BC, (b) Organopol 6400, (c) Organopol 6405, and (d) Praestol 611BC.

does not interact with the positively charged APs because of a strong electrostatic repulsion, and their mechanical mixture exhibit no increased flocculating effect.

\section{References}

[1] T. Schwartz and J. Francois, "Limite's de Solubilite des Polyacrylamide Partiellement Hydrolyses en Presence D'ions Divalents," Macromolecular Chemistry and Physics, Vol. 182, 1981, pp. 2775-2787. doi:10.1002/macp.1981.021821023

[2] G. Burrafato, S. Carminati, F. Bonaccorsi and T. P. Lockhart, "Evidence for Molecular $\mathrm{Cr}^{3+}$ Cross-Links in $\mathrm{Cr}^{3+} /$ polyacrylamide Gels," Macromolecules, Vol. 23, No.
8, 1990, pp. 2402-2406.doi:10.1021/ma00210a044

[3] V. F. Kurenkov, F. I. Churikov and S. V. Snigirev, "Sedimentation of Kaolin Suspension in the Presence of Partially Hydrolyzed Polyacrylamide and Aluminum Sulfate," Zhurnal Prikladnoi Khimii, St. Petersburg, Vol. 72, No. 5, 1999, pp. 828-831.

[4] V. A. Myagchenkov, E. V. Proskurina and G. V. Bulidorova, "Kinetic Aspects of Sedimentation in Model Disperse Systems Containing Polyacrylamide Flocculant," Chemistry and Technology of Water (Russian), Vol. 23, No. 5, 2001, pp. 453-491.

[5] L. Laorent and P. Paul, "Water-Soluble Organomineral Compositions and Their Use as Flocculants," FR Pat. Appl. No. 2788 779, IPC C08 L51/2, 2000. 
[6] J. R. Field and N. D. Smith, "Products and Process for Flocculation of Aqueous Suspensions", EP Pat. 0255 283, IPC C02F1/52, 1988.

[7] S. S. Perv, "Part Organic - Part Inorganic Coagulant," GB Pat. 2322 128, IPC C02F1/56, 1998.

[8] J. Q. Jiang and N. J. Graham, "Preliminary Evaluation of the Performance of How Pre-Polymerized Inorganic Coagulants for Lowland Surface Water Treatment," Water Science and Technology, Vol. 37, No. 2, 1998, pp. 121128. doi:10.1016/S0273-1223(98)00017-1

[9] J. Q. Jiang, S. Wang and A. Panagoulopoulos, "The Exploration of Potassium Ferrate (VI) as a Disinfectant/Coagulant in Water and Wastewater Treatment," Chemosphere, Vol. 63, No. 2, 2006, pp. 212-219. doi:10.1016/j.chemosphere.2005.08.020

[10] X. Chen, X. Y. Xu and Y. D. Fan, "Preparation and Application of Polymer Silicate Phosphate Ferric Sulfate Used in High-Viscosity Oil Refining Wastewater Treatment," Journal of Water Resource and Protection, Vol. 1, No. 3, pp. 195-202, 2009. doi:10.4236/jwarp.2009.13024

[11] I. M. Papisov and A. A. Litmanovich, "On Recognition Phenomena in Polymer-Minute Particle Interaction and Pseudo-Matrix Processes," Colloids and Surfaces A, Vol. 151, No. 3, 1999, pp. 399-408. doi:10.1016/S0927-7757(98)00851-6

[12] H. M. Buchhammer, G. Petzold and K. Lunkwitz, "Salt Effect on Formation and Properties of Interpolyelectrolytes Complexes and their Interaction with Silica Particles," Langmuir, Vol. 15, No. 12, 1999, pp. 4306-4310. doi:10.1021/la980992a

[13] B. L. Frankamp, O. Uzun, F. Ilhan, A. K. Boal and V. M. Rotello, "Recognition-Mediated Assembly of Nanoparticles Into Micellar Structures with Diblock Copolymers," Journal of the American Chemical Society, Vol. 124, No. 6, 2002, pp. 892-893. doi:10.1021/ja0170605

[14] H. Mori, A. H. Muller and J. E. Klee, "Intelligent Colloidal Hybrids via Reversible Ph-Induced Complexation of Polyelectrolyte and Silica Nanoparticles," Journal of the American Chemical Society, Vol. 125, No. 6, 2003, pp. 3712-3713. doi:10.1021/ja0297887

[15] I. A. Novakov, Ph. S. Radchenko and I. M. Papisov, "Formation of Polycomplexes Based Polyacrylamide and Aluminum Salts," Polymer Science (Russian), Series A, Vol. 45, No. 8, 2003, pp. 805-808.

[16] H. X. Ma, G. B. Yang, L. G. Yu and P. Y. Zhang, "Preparation and Characterization of Polyelectrolyte Multilayer Films Containing In-Situ Synthesized Nanoparticles of $\mathrm{Cu}(\mathrm{OH})_{2}$," Surface and Coatings Technology, Vol. 202, No. 24, 2008, pp. 5799-5803. doi:10.1016/j.surfcoat.2008.05.052

[17] D. J. Li, G. C. Xu and Y. H. Tao, "Studies on the Interaction between Nano-Ag and P(AMPS-MMA)," Acta Po- lymerica Sinica, No. 4, 2008, pp. 378-382. doi:10.3724/SP.J.1105.2008.00378

[18] J. M. Lehn, "Supramolecular Chemistry: Concepts and Perspectives," Weinheim; New York; Basel; Cambridge; Tokyo, 1995.

[19] I. A. Novakov, S. S. Radchenko, A. S. Pastukhov and Ph. S. Radchenko, "Properties of Aqueous Solutions of Polymer-Colloid Complexes of Polyethylenimine with Aluminum Hydroxychloride," Zhurnal Prikladnoi Khimii, St. Petersburg, Vol. 80, No. 11, 2007, pp. 1906-1909,.

[20] I. A. Novakov, Ph. S. Radchenko, A. S. Pastukhov and I. M. Papisov, "The Properties of Aqueous Solutions of Polymer-Colloid Complexes of Polyacrylamide with Poly (Aluminum Hydroxychloride)," Polymer Science, Series $A$, Russia, Vol. 47, No. 1, 2005. pp. 57-60.

[21] I. A. Novakov, Ph. S. Radchenko and I. M. Papisov, "A Study of the Composition of Polyacrylamide-PolyaluMilum Chloride Polymer-Colloid Complexes," Polymer Science, Series B, Russian, Vol. 49, No. 5-6, 2007, pp. 111-113. doi:10.1134/S1560090407050016

[22] I. A. Novakov, S. S. Radchenko, N. U. Bykadorov, Ph. S. Radchenko and O. P. Otchenashev, "Development of Technology of Preparing Poly (Aluminum Hydroxychloride) and Compositions on Its Basis and Their Use in Water Preparation and Purification Processes," Khimicheskaya Promyshlennost Segodnya, No. 2, 2004, pp. 10-22.

[23] I. A. Novakov, N. U. Bykadorov, S. S. Radchenko, O. P. Otchenashev et al., "Methods of Preparing Water-Soluble Reagent for Purification of Natural Water and Sewage and Phase Separation," RF Pat. 2174 105, IPC C02 F1/52, 2001 .

[24] I. A. Novakov, S. S. Radchenko and Ph. S. Radchenko, "Water-Soluble Polymer-Colloid Complexes of Aluminum Polyhydroxochloride and Polyacrylamide in Separation of Model and Real Dispersions," Zhurnal Prikladnoi Khimii, St. Petersburg, Vol. 77, No. 10, 2004, pp. 16991705.

[25] S. S. Radchenko, I. A. Novakov, Ph. S. Radchenko and E. V. Rybakova, "Method of Purifying Oil-Containing Sewage," RF Pat. 2288 182, IPC C02F 1/58, 2006.

[26] I. A. Novakov, S. S. Radchenko, A. S. Pastukhov and Ph. S. Radchenko, "Water Soluble Polymer-Colloid Complexes of Aluminum Polyhydroxochloride and Polyethylenimine in Separation of Dispersions at Low Ph," Zhurnal Prikladnoi Khimii, St. Petersburg, Vol.79, No. 3, 2006, pp. 464-469.

[27] S. S. Radchenko, I. A. Novakov, Ph. S. Radchenko, A. S. Pastukhov and A. S. Ozerin, "Method of Preparing Water-Soluble Reagent for Purification of Sewage and Phase Separation," RF Pat. 2292 309, IPC C02 F1/52, 2007.

[28] S. O. Zakharchenko, E. A. Litmanovich, Ph. S. Radchenko, A. S. Pastukhov, A. B. Zezin, I. A. Novakov and V. A. Kabanov, "Photon Correlation Spectroscopic Study of the Aggregative Stability of Colloidal Particles of 
Aluminum Pentahydroxide Chloride," Kolloidn Zhurnal, Vol. 64, No. 4, 2006, pp. 425-429.

[29] A. S. Ozerin, Ph. S. Radchenko, G. I. Timofeeva and I. A, Novakov, "A Study of Structural and Molecular Weight Characteristics of Poly (Aluminum Hydroxychloride) Nanoparticles by Small-Angle X-Ray Scattering and Sedimentation Analysis," Nanotechnologies in Russia, Vol. 4, No. 1-2, 2009, pp. 93-101. doi:10.1134/S1995078009010108

[30] S. S. Radchenko, I. A. Novakov, Ph. S. Radchenko, Le Van Cong, A. S. Ozerin and P. S. Zel'tser, "Interaction of
Aluminoxane Particles with Weakly Charged Cationic Polyelectrolytes," Journal of Applied Polymer Science, manuscript APP-2010-02-0574.2010, 2010.

[31] S. S. Radchenko, I. A. Novakov, Ph. S. Radchenko, A. S. Ozerin and E. V. Rybakova, " Method of Preparing Highbasicity Poly(Aluminum Hydroxychloride)," RF Pat. 2 362 738, IPC C01F 7/56, 2009.

[32] Yu. M. Chernoberezhnyi, A. V. Lorentsson and A. B. Dyagileva, "Coagulation of Sulfate Lignin by Aluminum Sulfate," Kolloidn Zhurnal, Vol. 62, No. 5, 2000, pp. 707-710. 